l'exemplaire cité plus haut de $\mathrm{S}^{\mathrm{t}}$-André-les-Alpes, et j'ajoute que trois autres exemplaires de cette mème localité forment encore ici, d'une façon très remarquable, le passage de cette forme, à lignes fines et distinctes, à la forme typique. C'est à ce caractère certainement qu'est dù l'aspect foncé de prohaskaella, la région brune costale portant des parties blanchâtres beaucoup plus réduites que chez subericinella vrai.

Je serais donc porté à considérer prohaskaella comme une forme foncée de subericinella; ce serait la variation extrême en sens opposé de celle du bord de l'Atlantique.

Une décision catégorique pourrait ètre fournie par les chenilles; malheureusement, en ce qui regarde prohaskaella, le $\mathrm{D}^{\mathrm{r}}$ ReBel ne donne qu'un renseignement négatif : aucune bruyère, dit-il, n'existait loin autour du lieu de capture. Il était préoccupé, en disant cela, de la séparer davantage d'ericinella, c'était assez superflu. Quant à subericinella, le Catalogue Staudinger de BAgonot porte manuscrite la mention suivante : Genista germanica. Je n'ai pu savoir d'où Piagonot avait eu ce renseignement et n'en ai pas d'autre sur ce point.

\title{
Nouveaux Cérambycides [CoL.] de la Chine méridionale. I ( $\left.{ }^{1}\right)$
}

par Maurice PIC.

Strangalia (Parastrangalia) apicicornis, n. sp. - Nitida, elytris sparse pubescentibus, rufo-testacea, antennis medio et apice nigris, elytrorum lateribus medio nigro maculatis.

Brillant, élytres éparsément pubescents, d'un roux testacé, avec le prothorax étroitement bordé de noir, les élytres maculés de noir sur leur milieu, la macule thoracique n'atteignant pas la suture et bordée d'une nuance plus claire que la couleur foncière. Antennes un peu plus longues que le corps, à articles 1 à ร̆ roussâtres, sommet du ̌̃e, $6^{\mathrm{e}}, 8^{\mathrm{e}}$ et $11^{\mathrm{e}}$ noirs, $9^{\mathrm{e}}$ et $10^{\mathrm{e}}$ blanchâtres. Tête large et pas très longue ; yeux gros. Prothorax plus long que large, rétréci et étranglé en avant, a ponctuation médiocre, serrée. Élytres assez larges aux épaules, progressivement rétrécis en arrière, échancrés au sommet, un peu creusés longitudinalement sur leur milieu, d'un testacé roussâtre plus clair par places, avec une macule noire au milieu des còtés. Pattes pas très longues. - Long. $12 \mathrm{~mm}$.

(1) Ces espèces, qui sont originaires du Yunnan, m’ont été communiquées par notre collègue $\mathbf{P}$. Guerri ; les types uniques font partie de sa collection. 
Cette espèce ressemble à $S$. Argodi Théry, mais les antennes sont moins foncées à la base, la coloration de l'avant-corps est roussâtre et les dessins foncés des élytres sont réduits.

Xylotrechus multisignatus, n. sp. - Opacus, niger, dense luteo pubescens et nigro multimaculatus, antennis pedibusque testaceis.

Mat, noir, densément revètu de pubescence jaune; élytres à transparence fauve par places; orné de nombreuses macule noires; antennes et pattes testacées. Tète assez étroite, munie sur le vertex de 4 petites carènes, les médianes jointes en avant; antennes courtes et grêles. Prothorax subglobuleux, un peu rétréci aux extrémités, orné d'une ligne médiane noire amincie en avant et élargie en arrière et, de chaque côté de celle-ci, sur le milieu, d'une macule noire. Élytres peu plus larges que le prothorax, courts, un peu atténués postérieurement, subarqués au sommet, ornés chacun des dessins noirs suivants: quatre macules antérieures disposées sur deux rangées, celles-ci en partie jointes, une macule postscutellaire commune, deux macules allongées, placées près du milieu, l'externe étant plus longue, un trait latéral antéapical, flanqué d'une petite macule interne. Pattes courtes. - Long. 1 כ̆ $\mathrm{mm}$.

Cette jolie espèce, très distincte par son système de coloration, peut se placer près de $\boldsymbol{X}$. diversesignatus Pic.

Hesperophanes Guerryi, n. sp. - Elongatus, subparallelus, nitidus, nigro-piceus, griseo-argenteo fasciculatus, antennis pedibusque rufescentibus.

Allongé, subparallèle, brillant, noir de poix, avec les membres roussâtres, orné d'une pubescence grise à reflets argentés, celle-ci disposée en mouchetures sur les élytres. Tête plus étroite que le prothorax, à ponctuation plus ou moins large et serrée, sillonnée entre les yeux; antennes dépassant les élytres d'un article, longuement et éparsement pubescentes. Prothorax court, sinué et faiblement tuberculé sur les còtés, inégal en dessus sur le disque, à ponc. tuation semblable à celle de la tête. Ély tres plus larges que le prothorax, longs, subparallèles, subarrondis au sommet, peu fortement et éparsément ponctués, la ponctuation s'effaçant vers l'extrémité, faiblement impressionnés à la hase en dedans des épaules. Pattes moyennes, pubescentes et ornées de longs poils clairs. - Long. $2.3 \mathrm{~mm}$.

Cette grande espèce peut se placer près de $\boldsymbol{H}$. cribricollis Bates, qui ne m'est connu que par la description; la forme des élytres semble plus parallèle et le revêtement est différent. 


\section{$2 \mathrm{BHL}$ Biodiversity Heritage Library}

Pic, Maurice. 1915. "Nouveaux Cérambycides [Col.] de la Chine méridionale.

I." Bulletin de la Société entomologique de France 1915, 313-314.

View This Item Online: https://www.biodiversitylibrary.org/item/36403

Permalink: $\underline{\text { https://www.biodiversitylibrary.org/partpdf/30263 }}$

\section{Holding Institution}

Smithsonian Libraries

\section{Sponsored by}

Smithsonian

\section{Copyright \& Reuse}

Copyright Status: NOT_IN_COPYRIGHT

This document was created from content at the Biodiversity Heritage Library, the world's largest open access digital library for biodiversity literature and archives. Visit BHL at https://www.biodiversitylibrary.org. 